\title{
Effects of $4 \%$ Icodextrin on Experimental Spinal Epidural Fibrosis
}

\author{
Turker KARANCI ${ }^{1}$, Bilal KELTEN ${ }^{2}$, Alper KARAOGLAN² ${ }^{2}$ Nilgun CINAR $^{3}$, Ahmet MIDI ${ }^{4}$, Veysel ANTAR ${ }^{5}$, \\ Hidayet AKDEMIR ${ }^{1}$, Zeynep Mine YALCINKAYA KARA ${ }^{6}$
}

\begin{abstract}
${ }^{1}$ Medicana International Istanbul Hospital, Department of Neurosurgery, Istanbul, Turkey ${ }^{2}$ Maltepe University, Faculty of Medicine, Department of Neurosurgery, Istanbul, Turkey ${ }^{3}$ Maltepe University, Faculty of Medicine, Department of Neurology,Istanbul, Turkey ${ }^{4}$ Bahcesehir University, Faculty of Medicine, Department of Pathology, Istanbul, Turkey ${ }^{5}$ istanbul Training and Research Hospital, Department of Neurosurgery, Istanbul, Turkey ${ }^{6}$ Sisli Etfal Training and Research Hospital, Department of Biochemistry, Istanbul, Turkey
\end{abstract}

\section{ABSTRACT}

AIM: The aim of this experimental study was to investigate whether spinal epidural $4 \%$ glucose polymer solution is effective in the prevention of postoperative fibrosis.

MATERIAL and METHODS: Twenty eight adult Wistar albino rats were randomly divided into two equal groups, including treatment and control. Both groups underwent L1 vertebral total laminectomy to expose the dura. Topical treatment group received 4\% icodextrin. Four weeks later, epidural fibrosis was examined in both groups histologically, biochemically and macroscopically.

RESULTS: Topical use of $4 \%$ icodextrin prevented significantly epidural fibrosis following the laminectomy operation.

CONCLUSION: Topical $4 \%$ icodextrin application inhibits postoperative epidural fibrosis with various mechanisms and prevents adhesions by playing barrier role between tissue surfaces through flotation. Our study is first to present evidence of experimental epidural fibrosis prevention with $4 \%$ icodextrin.

KEYWORDS: Epidural fibrosis, Icodextrin, Spine

\section{INTRODUCTION}

$\mathrm{E}$ pidural fibrosis is one of the important causes of persistent back pain or radicular pain, which result from laminectomy or hemilaminectomy and other surgical procedures performed for the treatment of the diseases that lead to compression of spinal cord or other nerve fibers (22). Development of fibrous tissue and adhesions in the epidural region is a normal reaction for healing process of the muscles over the spinal bone elements $(12,14,20,30)$. Nerve roots and the dorsal root ganglion are very sensitive against mechanical deformation caused by fibrosis. Epidural fibrosis leads to radicular pain by pulling, stretching or compressing the nerve root. No problem is observed in the early postoperative period; however, pain and even sensorial and motor deficits, may occur in the late postoperative period. Nerve or muscle complaints begin between 3 and 6 months and gradually progress $(2,26,30)$. Epidural fibrosis is a condition that increases the risk for peroperative complications such as failure hemostasis iatrogenic instability, dural laceration, and nerve root injury, and that requires more time for dissection and leads to difficulty for the surgeon (30). Many material, biologically inert or not, have been used as a barrier to prevent development of spinal epidural fibrosis $(5,21,31)$. It has been reported that free adipose tissue is used for this purpose 
both in the clinical and experimental studies $(5,19)$. On the other hand, it has been also reported that adipose tissue, the volume of which decreases in time, causes compression of the nerve acting as a piece of free disc (14). In the literature, substances used to prevent spinal epidural fibrosis include polylactic acid membrane, carboxymethyl cellulose, silastic membrane, fibrin glue, glucocorticoids, methyl methacrylate, spongostan, ADCON-L, urokinase, and sodium hyaluronate $(2,12,31)$.

A glucose polymer solution, 4\% icodextrin, was first used in 1980 s as an osmotic agent for the peritoneal dialysis of glucose polymers. It has been reported that $4 \%$ icodextrin solution reduces development of adhesions in the laparoscopic gynecological surgeries (8), and prevents development of intra-abdominal adhesions in the laparoscopic general surgical operations, as well (23). The aim of the present experimental study is to investigate whether $4 \%$ icodextrin plays a role in preventing the postoperative spinal epidural fibrosis.

\section{MATERIAL and METHODS}

The present experimental study was performed at Experimental Animals Laboratory of Taksim Training and Research Hospital after the approval of Istanbul University, Animal Experiments Local Ethics Committee was obtained (2009/77). The study included 28 male Wistar albino rats weighing between $220 \mathrm{~g}$ and $340 \mathrm{~g}$ with the mean weight of $265 \mathrm{~g}$. Biochemical analysis of the study was performed at the Biochemistry laboratory of our hospital, whereas the histopathological examination was performed at Department of Pathology of the Maltepe University

\section{Surgical Procedure}

For infection prophylaxis, a single dose of $50 \mathrm{mg} / \mathrm{kg}$ ceftriaxone (Rocephin, Roche, Turkey) was intraperitoneally (i.p) administered to the experimental animals 30 minutes prior to the surgical procedure. Sedation for the surgical procedure was provided by additional $10 \mathrm{mg} / \mathrm{kg}$ xylazine hydrochloride i.p. (Rompun, Bayer, Istanbul,Turkey) after 60 $\mathrm{mg} / \mathrm{kg}$ i.p. ketamine hydrochloride (Ketalar, Pfizer, Istanbul, Turkey) administration. After the experimental animals were fixed onto the surgical table, disinfection of the surgical area was provided by povidone iodine solution (POVIOD; 10\% polyvinylpyrrolidone-iodine complex, Saba, Turkey) after cleaning with povidone iodine scrub (MEDICA brush, 4\% chlorhexidine soap, MEDICA BV, Holland) for 10 minutes. The surgical area was covered with sterile cloths; approximately three $\mathrm{cm}$ skin incision was made over the spinous processes of L1-L2 vertebra on the midline and paraspinous muscles were cleaved via blunt dissection. Dura mater was exposed via total laminectomy performed to the $L 1$ vertebrae under the assistance of surgical microscope (Mentor II, Japan). After applying $2 \mathrm{ml}$ of $0.9 \%$ topical normal saline to the experimental animals in the control group and $2 \mathrm{ml}$ of $4 \%$ topical icodextrin (Eczacibasi/Baxter, Istanbul, Turkey) solution to those in the treatment group. The layers were duly closed layer by layer following surgical hemostasis. Experimental animals in the control and treatment groups were put in their cages and they underwent nursing. They were sacrificed with high dose $(75-100 \mathrm{mg} / \mathrm{kg})$ intraperitoneal thiopental sodium (Pentothal sodium, Abbott, Italy) after four weeks. Related vertebral columns were removed en-blocks for biochemistry and histopathological investigation. Experimental animals, in which dura mater laceration or nerve root injury developed during surgery and those in which infection was detected during decapitation, were excluded from the study.

\section{Groups of the Experimental Animals}

Twenty-eight experimental animals were randomly divided into two groups. Group $1(n=14)$ was the control group, of which eight were administered biochemical analysis (Group 1a) and six were administered histopathological investigation (Group 1b). Group 2 was the treatment group, of which eight were administered biochemical analysis (Group 2a) and six were administered histopathological examination (Group 2b).

\section{Biochemical Analysis}

The method defined by Edwards et al. (9) was used for the biochemical analysis. Dorsal dura mater of $L 1$ vertebrae of each experimental animal were removed to be $0.2 \times 0.2 \times 0.5 \mathrm{~cm}$ in size, washed with $0.9 \%$ normal saline, and dried with filter paper. Each tissue samples were separately put into Eppendorf tubes and stored in a deep freezer at $-80^{\circ} \mathrm{C}$. One day prior to the biochemical analysis, tissue samples were put into heatresistant tubes containing $1 \mathrm{~mL}$ of $6 \mathrm{M} \mathrm{HCl}$ solution, kept in the stove $\left(37^{\circ} \mathrm{C}\right)$ for 24 hours to be hydrolyzed, and $1 \mathrm{~mL}$ buffer solution [buffer solution was prepared in reference to the definition of Edwards et al. (9)] was added into the glass tubes for neutralization. The tissue was weighed to be approximately $10 \mathrm{mg}$, centrifuged at $+4^{\circ} \mathrm{C}, 3500 \mathrm{rpm}$ and for 10 minutes, and supernatants were obtained. These supernatants were measured by enzyme-linked immunosorbent assay (ELISA) method (between $15.6 \mathrm{ng} / \mathrm{mL}$ and $1000 \mathrm{ng} / \mathrm{mL}$ ) using an ELISA kit (E0621Ra, Wuhan, Uscn Life Science Inc.) (antibody covered 96-well plate rat hydroxyproline) and calculated by microplate reading device (ELx800, Bio-Tek Instruments Inc.) at $450 \mathrm{~nm}$ for absorbance values (Biomedical Technologies Inc., USA).

\section{Histopathological Examination}

Rydell criteria were used for the macroscopic evaluation of the specimens (Table I) (27).

All the histopathological examinations were performed by a histopathologist independent from the study protocol. The amount of epidural fibrosis in the laminectomy area and its association with the dura mater was compared according to the histopathological classifications, and the outcomes were statistically analyzed. The vertebral colon, which had been removed as block for histopathological examination, was decalcified for five days (Shanden TBD-2) after being kept in $10 \%$ buffered formaldehyde for four days. Three samples (from mid, proximal and distal parts), $2 \mathrm{~mm}$ in thickness, were obtained from the laminectomy area transverse to the spinal cord, and they were placed in the cassettes. These samples were washed under running water for three hours to be decalcified. Thereafter, they were monitored with automatic 
tissue monitoring device (Shandenexelsior ES) for 13 hours. During this procedure, tissues were exposed in turn to formaldehyde twice for 30 minutes, to alcohol six times for 60 minutes, to xylene three times for 60 minutes, and to paraffin once for 60 minutes and twice for 80 minutes. The tissues were embedded in paraffin blocks following the monitoring process, and sections were obtained via $3 \mu$ microtome (Shanden Fine SSE 325). The hematoxylin eosin (HE) stain was used for routine histopathological examination, whereas trichrome stain was used to evaluate epidural fibrosis. Epidural fibrosis, fibroblast density and granulation tissue in the laminectomy area was evaluated under light microscope (OLYMPUS CX31; $1 \mathrm{hpf}=0.228 \mathrm{~mm}^{2}$ ). Histopathological classification of epidural fibrosis was performed in reference to the definition of $\mathrm{He}$ et al. (15) (Table II).

The classification defined by Hinton et al. (16) was used for the histopathological staging of epidural fibrosis according to the fibroblast cell density. In accordance with this classification, stage 1 corresponds to a fibroblast count less than 100 , whereas stage 2 corresponds to 100 to 150 fibroblasts, and stage 3 corresponds to a fibroblast count higher than 150 (Table III) (16). The mean fibroblast count was calculated by counting the fibroblasts in three different areas under $\times 40$ magnification under light microscope.

\section{Statistical Analysis}

Data were analyzed using statistical package for social sciences version 11.0 software package program (SPSS Inc., Chicago, IL, USA). Two-sided Wilcoxon test and MannWhitney $U$ test were used for the intergroup comparison of hydroxyproline levels. Other intergroup comparisons were performed using t-test and Kolmogorov-Smirnov method. A $p$ value $<0.05$ were considered significant.

\section{RESULTS}

\section{Clinical Results}

Postoperative neurological deficit was not detected on the (BBB) behavioral evaluation of all experimental animals. Neither mortality nor morbidity was observed in any of the experimental animals in the control and treatment groups.

\section{Histopathological Results}

The results of control and treatment groups were compared using the Rydell criteria for macroscopic evaluation. In the treatment group no $4 \%$ icodextrin solution-associated complication was detected in any of the experimental animals. Various degrees of epidural fibrosis were observed in all experimental animals macroscopically. While, epidural fibrosis was more intensive in the control group, it was less in the treatment group. Distribution of stages of epidural fibrosis among experimental animals was as follows: four of the experimental animals in the control group were stage 2 , one was stage 1 and one was stage 3 , whereas two of the experimental animals in the treatment group were stage 0 , one was stage 2 and three were stage 1 (Table IV).

Stage 3 epidural fibrosis was detected in most of the experimental animals in the control group both with hematoxylin eosin (Figure 1,2) and with Masson's trichrome (Figure 3) stains. The epidural fibrosis extended towards to the dura mater beneath the paraspinal muscles and became adherent. Spaces were detected between the paraspinal dura mater and the neighboring muscle layers and nerve roots of the experimental animals in the treatment group. It was observed that there were clusters of mild fibroblast proliferation extending in patches to the dura mater and to the neighboring tissues (Figure 3). When the histopathological outcomes of the control and the treatment groups were compared in terms of epidural fibrosis, it was found that those in the treatment group were

Table I: Macroscopic Classification According to the Rydell Criteria (27)

\begin{tabular}{ll}
\hline Stage 0 & No scar tissue in the duramater \\
\hline Stage 1 & $\begin{array}{l}\text { Scar tissue in the duramater but dissected } \\
\text { easily }\end{array}$ \\
\hline Stage 2 & $\begin{array}{l}\text { Scar tissue in the duramater, difficult dissection } \\
\text { together with impaired duramater }\end{array}$ \\
Stage 3 & $\begin{array}{l}\text { Adhered scar tissue in the duramater and } \\
\text { cannot be dissected }\end{array}$ \\
\hline
\end{tabular}

Table II: Histopathological Classification of Epidural Fibrosis According to the He et al. Criteria (15)

\begin{tabular}{ll}
\hline Stage 0 & No fibrosis influencing the duramater \\
\hline Stage 1 & $\begin{array}{l}\text { Fine fibrous bands between fibrous tissue and } \\
\text { duramater }\end{array}$ \\
\hline Stage 2 & $\begin{array}{l}\text { Continuous adhesion in less than } 2 / 3 \text { of the } \\
\text { laminectomy defect }\end{array}$ \\
\hline Stage 3 & $\begin{array}{l}\text { Adhesion of the fibrous tissue in more than } 2 / 3 \\
\text { of the laminectomy defect and/or fibrous tissue } \\
\text { reaches to the nerve roots }\end{array}$ \\
\hline
\end{tabular}

Table III: Fibroblast Classification in Reference to the Hinton Criteria (16)

\begin{tabular}{ll}
\hline Stage 1 & $<100$ fibroblast \\
\hline Stage 2 & $100-150$ fibroblast \\
\hline Stage 3 & $>150$ fibroblast \\
\hline
\end{tabular}

Table IV: The Stages of Epidural Fibrosis on Macroscopic Evaluation

\begin{tabular}{lcc}
\hline Stage & Control group $(\mathbf{n}=\mathbf{6})$ & Treatment group $(\mathbf{n}=\mathbf{6})$ \\
\hline Stage 0 & 0 & 2 \\
\hline Stage 1 & 1 & 3 \\
\hline Stage 2 & 4 & 1 \\
\hline Stage 3 & 1 & 0 \\
\hline
\end{tabular}




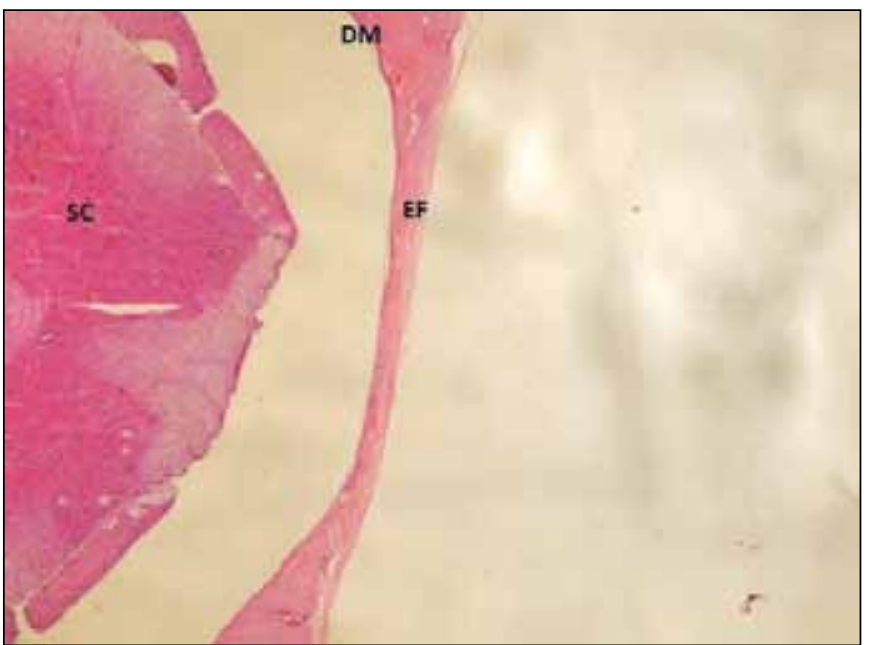

Figure 1: In laminectomy Icodextrin $4 \%$ in the group are monitored membranous thin fibrous layer (HEx40 magnification). EF: epidural fibrosis, SC: spinal cord, DM: dura mater.

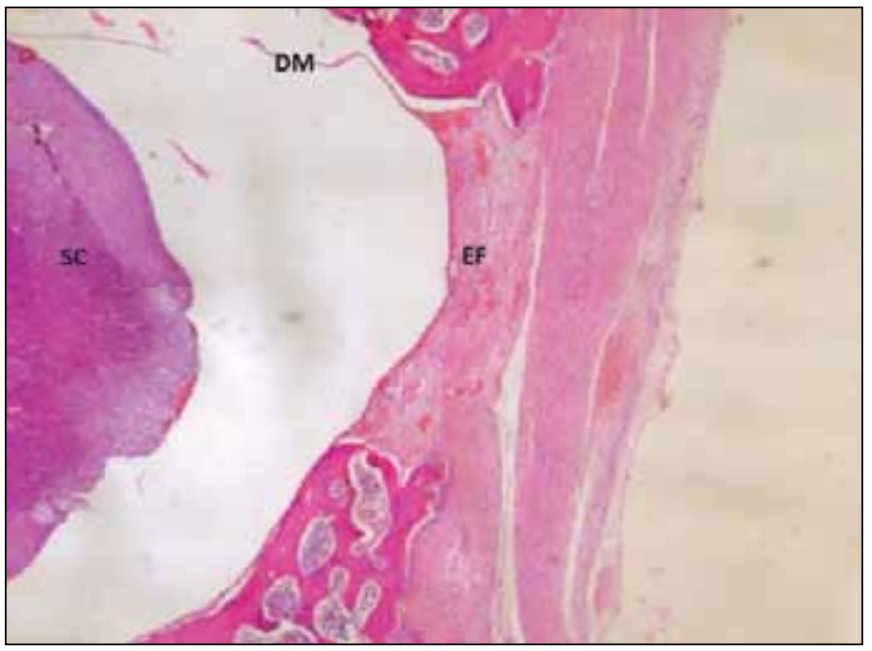

Figure 2: Thick fibrous membranous layer is selected in the control group, the laminectomy (HEx40 magnification).

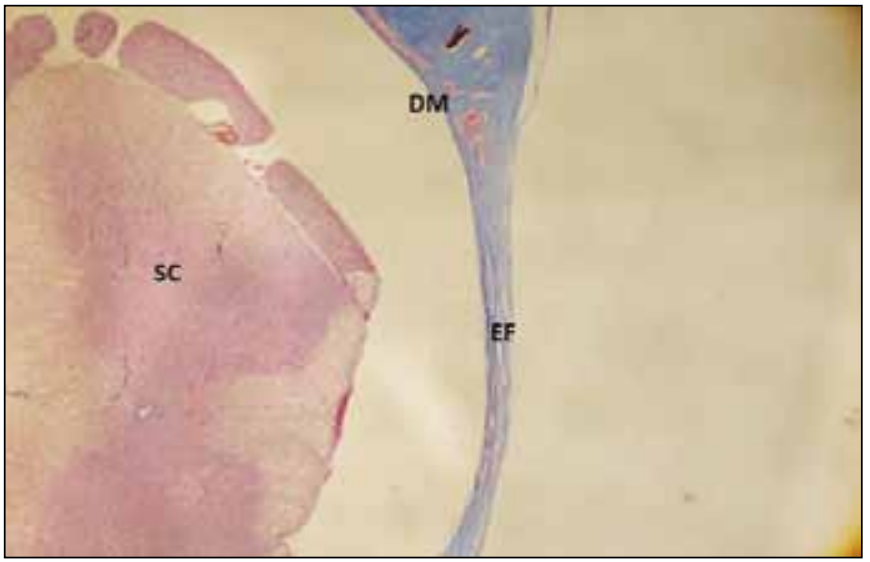

Figure 3: In laminectomy lcodextrin 4\% in the group are monitored thin fibrous membranous structure (Trichromex100 magnification). significantly lower $(p<0.05)$. Distribution of the stages of epidural fibrosis among experimental animals was as follows; five of the experimental animals were stage 2 and one was stage 3 in the control group, whereas four of the experimental animals were stage 1 and two were stage 0 in the treatment group (Table V).

The number of microscopic fibroblasts was calculated according to the mean number of the fibroblasts in the groups (Table VI). Fibroblast count was found to be stage 3 in two (Figure 4), stage 2 in three, and stage 1 in one of the experimental animals in the control group. On the contrary, stage 3 was identified in none of the experimental animals in the treatment group, stage 2 was counted in four, and stage 1 was counted in two experimental animals. Fibroblast intensity was significantly lower in the treatment group compared to that in the control group $(\mathrm{p}<0.005)$.

Table V: The Stages of Epidural Fibrosis on Microscopic Evaluation

\begin{tabular}{lcc} 
Stage & Control group $(\mathbf{n}=6)$ & Treated \\
\hline Stage 0 & 0 & 2 \\
\hline Stage 1 & 0 & 4 \\
\hline Stage 2 & 5 & 0 \\
\hline Stage 3 & 1 & 0 \\
\hline
\end{tabular}

Table VI: Microscopic Fibroblast Count of the Treatment and Control Groups

\begin{tabular}{lcc}
\hline Stage & Control group $(\mathbf{n}=6)$ & Treated group $(\mathbf{n}=\mathbf{6})$ \\
\hline Stage 1 & 1 & 2 \\
\hline Stage 2 & 3 & 4 \\
\hline Stage 3 & 2 & 0 \\
\hline
\end{tabular}

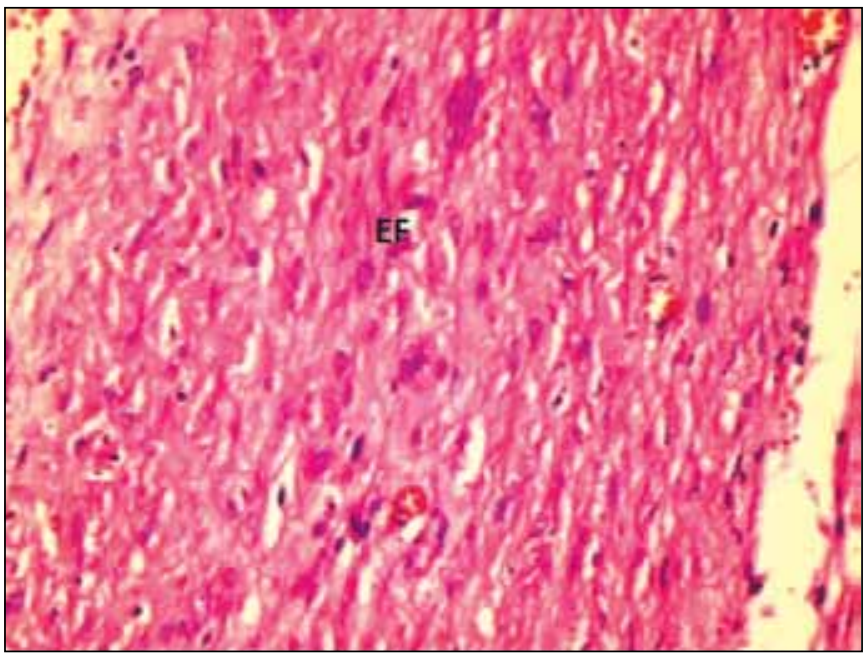

Figure 4: Intense presence of fibroblasts is observed in the control group (HEx400). 


\section{Biochemical Analysis}

The mean hydroxyproline value was $367.5 \pm 8.4 \mathrm{ng} / \mathrm{mL}$ in the control group and $243.75 \pm 9 \mathrm{ng} / \mathrm{mL}$ in the treatment group, The mean hydroxyproline value was significantly lower in the treatment group compared to that in the control group $(p<0.001)$ (Figure 5).

\section{- DISCUSSION}

It has been reported that postoperative epidural fibrous tissue may cause persistent back and leg pain and may lead to substantial intraoperative complications by making the reoperation difficult $(3,10,13,20,28)$. Fibroblastic cell migration that results from paraspinal muscles and chemotactic factors, which are released due to the erythrocyte and thrombocyte degradation after excessive epidural bleeding, is the origin of the epidural fibrosis following laminectomy. Adhesions also may occur due to the fibrous connective tissue hyperplasia. Fibrous connective tissue is able to repair vertebral lamina defects following laminectomy. Fibroblasts are changed into fibrocytes via collagen fibril production. Simultaneously, fibrous connective tissue turns into scar tissue. Epidural fibrous tissue may adhere to the dura mater or nerve roots in the vertebral channel and may change into laminectomy membrane in the long term. It has been reported that, this secondary membrane leads to spinal stenosis, dural compression and restriction of nerve root mobility $(10,12$, $17,26)$. Since the recurrent surgical procedures that would be performed to remove secondary compression caused by epidural fibrosis might also lead to an increment in fibrosis, trying to prevent such a condition during the initial surgery would be more reasonable (18). Until today, various materials and drugs have been used in many studies to prevent epidural fibrosis following vertebra surgery. In many studies, for this purpose, as solid barriers autogenous adipose tissue, polyvinyl alcohol, hydrogel membrane, polytetrafluoroethylene membrane, polylactic acid membrane, and vicryl mesh, as viscose solution sodium hyaluronate and ADCON-L, as fibrinolytic agent gel recombinant tissue plasminogen activator, and urokinase, as hemostatic agents gelatin sponge and microfibrillary collagen, and as anti-inflammatory agents methylprednisolone, triamcinolone, prednisolone, ketoprofen

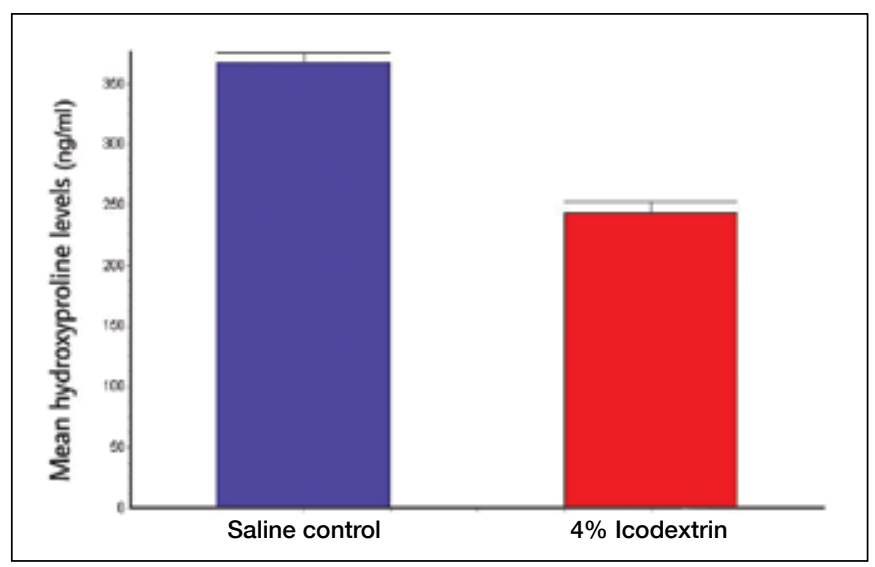

Figure 5: Mean hydroxyproline value. and dexamethasone have been used. Another experimental study has reported that low dose radiotherapy and $\mathrm{CO}_{2}$ laser application might reduce epidural fibrosis (6). Despite the successful results obtained in many of these studies, low dose radiotherapy and $\mathrm{CO}_{2}$ laser application are not used in the routine clinical practice because of insufficient efficacy consistent with clinical improvement in human $(2,12,14,30)$. The present experimental study investigated the effect of $4 \%$ icodextrin solution on prevention of postoperative spinal epidural fibrosis. In the present study, when histopathological outcomes of the control and the treatment groups were compared in terms of epidural fibrosis, it was found that those in the treatment group were significantly lower $(p<0.05)$. In addition to, the mean hydroxyproline value was significantly lower in the treatment group compared to that in the control group $(p<0.001)$. While to the best of our knowledge, there is no similar experimental study in the literature our results could not be compare statistically other studies. Although autogenous adipose tissue has been most commonly used to prevent epidural fibrosis until today, it is also known that adipose tissue reduces epidural adhesions, but has no fibrosis-preventing effect, and even may lead to cauda equina syndrome. Bryant et al. (4) used free autogenous adipose grafts in 44 patients and based on their short and long-term follow-up period they concluded that this tissue was well tolerated and prevented extension of epidural fibrous tissue to the spinal channel by being revascularized. Prusick et al. (25) used free autogenous adipose tissue in two cases and reported cauda equina syndrome due to the migration of this tissue into the spinal channel. Moreover, another one study showed that free adipose tissue used to prevent epidural fibrosis in 99 patients who underwent surgical practise because of lumbar disc herniation (LDH) was clinically ineffective $(12,14,30)$. In another study, the efficacy of the substance used to prevent epidural fibrosis following experimental laminectomy has been investigated via macroscopic evaluation, histopathological fibrosis classification, fibroblast count, and biochemical hydroxyproline levels (29). There was not any obvious adhesion in the rats of mitomycin-C (MMC) group, but severe peridural adhesions were found in those in the 5-fluorouracil (5FU) and control groups. The content of hydroxyproline, the area of peridural scar tissue, and the number of fibroblasts in the MMC group were significantly lower than those in the 5FU and control groups. They concluded that the topical application of $\mathrm{MMC}$ rather than 5FU may be a successful method of preventing postlaminectomy peridural adhesions. In the present study, as well, the same parameters were used to investigate the efficacy of $4 \%$ icodextrin solution. Kuivila et al. (21) investigated the efficacy of adipose graft and heparinized material to prevent epidural fibrosis in the experimental laminectomy model, and reported that adipose tissue was more effective than heparinized material. Besides the studies in the literature reporting that adipose tissue placed into the laminectomy area prevents epidural fibrosis, it has also been reported that the hematoma in the surgical area is an important predisposing risk factor for the development of fibrosis (22). Providing accurate hemostasis to prevent local hematoma in the surgical area is the most important protective factor against epidural fibrosis. In the present study as well, bleeding 
control was precisely performed to prevent hematoma in the surgical area. In an experimental study performed to compare the efficacies of gelfoam and autogenous adipose grafts in the prevention of epidural fibrosis, it has been reported that gelfoam did not prevent fibrosis, whereas adipose tissue prevented the extension of adhesion to the spinal channel (19). In their experimental laminectomy model, Gerszten et al. (13) showed that peroperative low dose external radiation (700 cGy) reduced epidural fibrosis. Akeson et al. (1) used absorbable cover plaques having antifibrinolytic efficacy and topical HMW HA in their experimental study performed to prevent epidural fibrosis. The results were found similar to each other in the HMW HA group and were quite significant as compared to the control group. They also observed that epidural fibrous tissue was distant from the epidural space and adhered to the adjacent tissues instead of dura mater (1).

A clinical study performed to prevent epidural fibrosis investigated the effect of ketoprofen, a systemic non-steroid anti-inflammatory drug, and showed that ketoprofen reduced the postoperative anti-inflammatory cell infiltration, scar formation, and bone regeneration, whereas no reduction was observed in the extensive dura mater adhesion despite the decrease in the thickness of epidural fibrosis (17). Foulkes and Robinson reported that irrigation of the laminectomy area with long-acting steroids decreased the postoperative use of narcotics and shortened the length of the hospital stay due to their non-steroid anti-inflammatory and pain mediatorsuppressing effects (11). Weiss et al. used sodium HA solution in their experimental laminectomy model, measured the adhesion area and histopathological thickness of the tissue surrounding the nerve roots, and observed a significant reduction in the development of epidural fibrosis (32).

In a prospective, multi-center, double blind, controlled study, de Tribolet et al. applied ADCON-L to the cases that underwent lumbar discectomy and reported that this gel prevented postoperative epidural fibrosis and provided better clinical outcomes as compared to the control cases (7).

Likewise, 4\% icodextrin solution used in the present study acted as a barrier against adhesions both in and out of the laminectomy area and kept the tissue surfaces separate from each other by floatation, and thus, reduced epidural fibrosis. In their experimental study performed to prevent epidural fibrosis, Kemaloglu et al. (20) reported that topical recombinant tissue plasminogen activator (rt-PA) was effective and reliable, and that a thrombolytic therapy including rt-PA might play an important role in preventing arachnoiditis and epidural fibrosis following spinal surgery. In an experimental peritonitis model, it has been suggested that $4 \%$ icodextrin solution prevents epidural fibrosis by profibrinolytic stimulation after stimulating rt-PA synthesis (24). In the present experimental laminectomy model which was planned based on this hypothesis, histopathological (macroscopic and microscopic) and biochemical outcomes revealed that $4 \%$ icodextrin solution prevented postoperative epidural fibrosis likely due to profibrinolytic stimulation. The $4 \%$ icodextrin solution used in the present study stimulates rt-PA synthesis in the surgical area and prevents the development of epidural fibrous tissue that is likely to occur after the hemolysis of the blood products following fibrinolytic activation. This theory is also compatible with that defined by La Rocca and Macnab (22). In the present study, it was detected that epidural fibrosis completely surrounded the dura mater, filled the epidural space, progressed under the pedicle, and extended towards to the spinal roots in the control group, whereas the fibrous tissue developed over the dura mater was thinner in those underwent $4 \%$ icodextrin application. Moreover, the mean hydroxyproline level was significantly lower in the experimental animals in the $4 \%$ icodextrin treatment group compared to that in the control group. It has been reported that $4 \%$ icodextrin solution, which has been used as a peritoneal dialysis solution for a long time in the literature, reduces adhesion in the laparoscopic gynecological surgery (8), and prevents intraabdominal adhesions in the general surgery (23). Di Zerega et al. (8) used icodextrin in their experimental study and reported that this solution less inhibited the phagocytic functions as compared to the solutions including glucose, and as well as less glycosylated the peritoneal proteins as compared to the glucose-based solutions. Accordingly, they reported that adhesions were less frequently in the laparoscopic gynecologic surgery performed with icodextrin lavage. Moreover, multicenter ARIEL (Adept Registry for Clinical Evaluation) clinical studies reported that $4 \%$ icodextrin solution was useful to reduce adhesions following routine major abdominal surgeries (23).

\section{- CONCLUSION}

Local application of $4 \%$ icodextrin solution in the experimental laminectomy model prevents the adhesion in and out of the surgical area by acting as a barrier by means of keeping the tissue surfaces separate from each other via flotation. Moreover, it stimulates rt-PA synthesis in the surgical area and prevented postoperative epidural fibrous tissue that would develop by the hemolysis of blood products following fibrinolytic activation. Beside the fact that the present study, which is one of the first study in the literature, would illuminate further similar experimental studies by demonstrating the reducing effect of topical $4 \%$ icodextrin solution in postoperative epidural fibrosis, multi-center, randomized, placebo-controlled, double-blind clinical studies are needed for this solution to be used in spinal surgical procedures in humans.

\section{REFERENCES}

1. Akeson WH, Massie JB, Huang B, Giurea A, Sah R, Garfin SR, Kim CW: Topical high-molecular-weight hyaluronan and a roofing barrier sheet equally inhibit postlaminectomy fibrosis. Spine J 5: 180-190, 2005

2. Alkalay RN, Kim DH, Urry DW, Xu J, Parker TM, Glazer PA: Prevention of postlaminectomy epidural fibrosis using bioelastic materials. Spine (Phila Pa 1976) 28:1659-1665, 2003

3. Barnett GH, Hardy RW, Little JR: Thoracic canal stenosis. J Neurosurg 66:338-344, 1987 
4. Bryant MS, Bremer A, Nguyen TQ: Autogenic fat transplants in the epidural space in routine lumbar spine MR imaging assessment. AJNR 9:169-178, 1988

5. Bryant MS, Bremer A, Nguyen TQ: Autogenic fat transplants in the epidural space in routine lumbar spine surgery. Neurosurgery 13: 367-370, 1983

6. Colak A, Bavbek M, Aydin NE, Renda N, Acikgoz B: Effect of $\mathrm{CO} 2$ laser on spinal epidural fibrosis. Acta Neurochir (Wien) 138: 162-166, 1996

7. De Tribolet N, Porchet F, Lutz TW, Gratzl O, Brotchi J, van Alphen HA, van Acker RE, Benini A, Strommer KN, Bernays RL, Goffin J, Beuls EA, Ross JS: Clinical assessment of a novel anti adhesion barrier gel prospective randomized multicenter clinical trial of ADCON-L to inhibit postoperative peridural fibrosis and related symptoms after lumbar discectomy. Am J Orthop 27:111-129,1998

8. Di Zerega GS, Verco SJS, Young P, Kettel M, Kobak W, Martin D, Sanfilippo J, Peers EM, Scrimgeour A, Brown CBA: Randomized controlled pilot study of the safety and efficacy of $4 \%$ icodextrin solution in the reduction of adhesions following laparoscopic gynaecological surgery. Human Reproduction 17: 1031-1038, 2002

9. Edwards CA, O'Brien WD Jr: Modified assay for determination of hydroxyproline in a tissue hydrolyzate. Clin Chim Acta 10: 161-167, 1980

10. Epstein NE, Schwall G: Thoracic spinal stenosis. Diagnostic and treatment challenges. J Spinal Disord 7: 259-269, 1994

11. Foulkes GD, Robinson JS Jr: Intraoperative dexamethasone irrigation in lumbar microdiskectomy. Clin Orthop 261:224228, 1990

12. Geisler FH: Prevention of epidural fibrosis: Current methodologies. Neurol Res 21:9-22, 1999

13. Gerszten PC, Moossy JJ, Flickinger JC, Gerszten K, Kalend A, Martinez AJ: Inhibition of peridural fibrosis after laminectomy using low-dose external beam radiation in a dog model. Neurosurgery 46: 1478-1485, 2000

14. Gorgulu A, Simsek O, Cobanoglu S, Imer M, Parsak T: The effect of epidural free fat graft on the outcome of lumbar disc surgery. Neurosurg Rev 27: 181-184, 2004

15. He Y, Revel M, Loty B: A quantitative model of postlaminectomy scar formation effects of a non steroidal antiinflammatory drug. Spine 20: 557-563, 1995

16. Hinton JL, Warejcka DJ, Mei Y, Mc Lendon RE, Laurencin C, Lucas PA, Robinson JS: Inhibition of epidural scar formation after lumbar laminectomy in the rat. Spine 20:564-570, 1995

17. Huang SC, Lai HC, Tsai IC: Treatment of pseudomonas keratoscleritis after pterygium excision. Cornea 18: 608-611, 1999

18. Jayson MIV: The lumbar spine and back pain. $3^{\text {rd }}$ edn. UK: Churchill-Livingstone, 1987:463
19. Keller JT, Dunsker SB, Mewhorter JM, Ongkıko CM, Saunders $\mathrm{MC}$, Mayfield $\mathrm{FH}$ : The fate of autogenous grafts to the spinal dura. J Neurosurg 49: 412-418, 1978

20. Kemaloglu S, Ozkan U, Yılmaz F, Nas K, Gur A, Acemoglu H, Karasu H, Cakmak E: Prevention of spinal epidural fibrosis by recombinant tissue plasminogen activator in rats. Spinal Cord 41: 427-431, 2003

21. Kuivila TE, Berry JL, Bell GR, Steffec AD: Heparinized materials for control of the formation of the laminectomy membrane in experimental laminectomies in dogs. Clin Orthop Relat Res 236:166-174,1988

22. La Rocca H, Macnab I: The laminectomy membrane. Studies in its evolution, characteristics, effects and prophylaxis in dogs. J Bone Joint Surg Br 3: 545-550, 1974

23. Menzies D, Hidalgo Pascual M, Walz MK, Duron JJ, Tonelli F, Crowe A, Knight A: Use of icodextrin $4 \%$ solution in the prevention of adhesion formation following general surgery: From the multicentre ARIEL Registry. Ann R Coll Surg Engl 88: 375-382, 2006

24. Müller SA, Treutner $\mathrm{KH}$, Haase $\mathrm{G}$, Kinzel $\mathrm{S}$, Tietze $\mathrm{L}$, Schumpelick V: Effect of intraperitoneal anti-adhesive fluids in a rat peritonitis model. Arch Surg 138: 286-290, 2003

25. Prusick VR, Lint DS, Bruder J: Cauda equina syndrome as a complication of free epidural fat grafting. J Bone Joint Surg 70: 1256-1258, 1988

26. Rodgers KE, Robertson JT, Espinoza T, Oppelt W, Cortese S, di Zerega GS, Berg RA: Reduction of epidural fibrosis in lumbar surgery with Oxiplex adhesion barriers of carboxymethyl cellulose and polyethylene oxide. Spine J 3: 277-284, 2003

27. Rydell N: Decreased granulation tissue reaction after installment of hyaluronic acid. Acta Orthop Scand 41:307311,1970

28. Smith DE, Godersky JC: Thoracic spondylosis an unusual cause of myelopathy. Neurosurgery 20: 589-593, 1987

29. Sun $Y$, Wang LX, Wang L, Sun SX, Cao XJ, Wang P, Feng $L$ : A comparison of the effectiveness of mitomycin $C$ and 5-fluorouracil in the prevention of peridural adhesion after laminectomy. J Neurosurg Spine 7: 423-428, 2007

30. Temel SG, Ozturk C, Temiz A, Ersozlu S, Aydinli U: A new material for prevention of epidural fibrosis after laminectomy. J Spinal Disord Tech 19: 270-275, 2006

31. Trotter EJ, Crissman J, Robson D, Babish J: Influence of non biologic implants on laminectomy membrane formation in dogs. Am J Vet Res 49: 634-643, 1988

32. Weiss C, Dennis J, Suros JM, Denlinger J, Badia A, Gross $\mathrm{J}$ : Sodium hyaluronate for the prevention of postlaminectomy scar formation. Trans Orthop Res Soc 13: 44-47,1989 